\title{
Techniques of Oil Spill Response in the sea
}

\author{
$\mathrm{Obi}^{1}$, E. O., Kamgba ${ }^{2}$, F. A., and $\mathrm{Obi}^{3}$, D. A. \\ ${ }^{1 \& 2}$ Dept. of Physics Cross River University of Technology, Calabar, Nigeria \\ ${ }^{3}$ Dept. of Geology University of Calabar, Calabar, Nigeria
}

\begin{abstract}
The techniques of combating any kind of oil spill in a marine environment have been studied. It was established that the mechanical method of response using oil booms and skimmers is the best method as this removes the oil completely from the marine environment. However, this method cannot be applied for all oil spills. Other methods applicable are by the methods of biodegradation, chemical dispersants and in-situ burning. This paper explains clearly under what conditions we may apply any of these methods. This is usually done taking into consideration the oil type, the concentration of the oil slick on the surface of the water, the environmental and weather conditions. Apart from the mechanical method, the other three methods have their negative impact on the environment. The negative effects ranges from the destruction of the marine environment, to destruction of marine life and in fact destruction and pollution of the atmosphere. Consequently, the negative effects of the combating technique or techniques have to be carefully evaluated before usage.
\end{abstract}

Key words: biodegradation, chemical dispersants, in-situ burnin, Oil booms and skimmers.

\section{Introduction:}

Oil spills are different in their severity and extent of damage. This is as the result of the variation in oil types, location, and weather conditions involved. The spread and behavior of spilled oil in the sea or marine environment is governed by physical, chemical, and biological processes. These processes depend on the oil properties, hydrodynamics, meteorological and environmental conditions. The physical processes include advection, diffusion and spreading, the chemical processes are evaporation, dissolution and emulsification, while the major biological process is biodegradation.

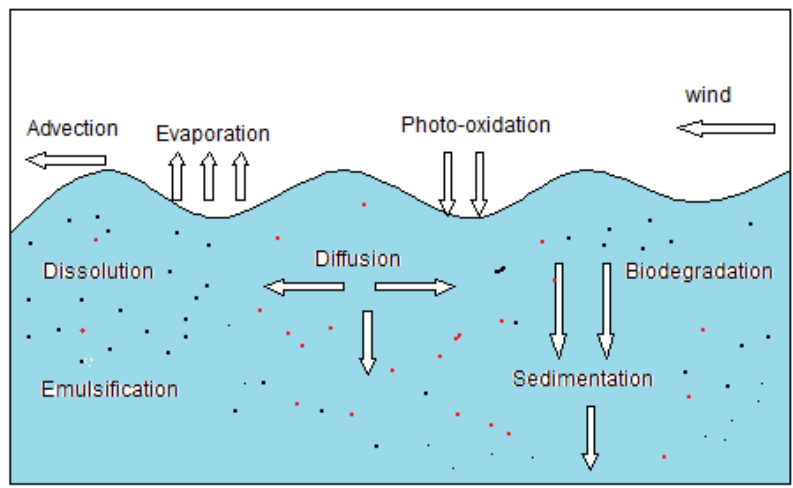

Figure 1: Oil spill processes

These processes begin to transform the oil by a process called weathering. Over a long period of time the combined action of weathering and biodegradation can eliminate most of the spilled oil. The rate at which these processes occur and the extent to which they proceed depends: (1) the chemical and physical properties of the original crude oil, (2) the prevailing environmental conditions, (3) the condition of the oil that is spilled. These factors are interrelated and it is their combination that causes different crude oils to behave in different ways at different oil spills. If the oil is not contained on time, it may spread to environmentally sensitive areas to pollute such areas as beaches, biologically sensitive areas and estuaries causing severe damage. (Lewis et al, 1997: Tkalich et al, 2003: Clark, 1992: Fay, 1971).

The spillage of oil is dangerous to the economy and environment of many Nations, consequently, a number of cleanup methods have been developed. These methods may be grouped into four major categories: (i) allow the oil to undergo biodegradation (ii) recovery of oil from the sea surface by the use of oil booms and skimmers (mechanical method); (iii) by use of chemical dispersants (iv) by control burning (in-situ burning) of the oil, thereby causing the oil to evaporate into the atmosphere (this process pollutes the atmosphere). The four methods given above are directed at removing the oil from the water surface, but only the second method removes the oil completely out of the marine environment. The first method disintegrates and consequently 
removes the oil from the marine environment but it takes a long time, by the time that the oil is eventually removed from the environment much harm might have been done. The third and fourth methods simply displace the oil from the water surface to the water column, seabed or the atmosphere. The process of applying the first, third or fourth methods may adversely affect the marine organisms. Consequently, the negative impacts of the combating techniques application have to be carefully calculated before the actual usage. In many cases, a mathematical model is the readily available tool for a rapid computation of the fate of the spilled oil, and for simulation of the various cleanup operations. (Tkalich et al, 2003)

Early scientists used only semi empirical formulas to formulate different mathematical models of the dynamics of oil spillage (Fay, 1971; Mackay et al, 1980; Lehr et al, 1984). Nowadays, Navier-Stokes equations can be used to simulate an oil slick dynamics model. Furthermore, it is now a common practice to use Eulerian coordinates for solution of the partial differential equations, in contrast to the tracking of the oil slick drifting that traditionally employs the Lagrangian approach. (Stolzenbach et al, 1977).

\section{Methods Of Cleaning Oil Sapillage}

There are many ways that oil spillage can be cleaned. However, broadly speaking there are four main methods of containing oil spillage in a marine environment. These methods include:

2.1 Biodegradation: Biodegradation is the process whereby most of the components of the spilled oil is broken down by bacteria and other microorganisms into harmless substances such as fatty acids and carbon dioxide. The rate at which spilled oil undergoes biodegradation depends on the type of oil, its concentration and the type of hydrocarbons it contains. We can speed up the natural process of biodegradation by adding nutrients like nitrogen and phosphorous. These nutrients stimulate growth of the microorganisms concerned. (Lee et al, 1989a: Lee et al, 1989b: Biello, 2010)

\section{2}

2.2 Mechanical method: The best method of cleaning oil spillage is by mechanical method. This is because the mechanical method completely removes the oil from the marine environment. However this method can only be applied when the sea is calm. The mechanical method cannot be applied under the following conditions. (1) rough sea waves (2) high wind velocity (3) high water waves. The method requires the use of oil booms and skimmers. In this method the oil is captured and stored until it can be disposed of properly. There are various types of oil booms that can be used either to surround and isolate a slick, or to block the passage of a slick to vulnerable areas such as fish-farm or other environmentally sensitive areas. Boom types vary from inflatable neoprene tubes to solid, but buoyant material. Some are designed to sit flush on tidal flats while others are applicable to deeper water and have skirts which hang down about a meter below the waterline. Skimmers float across the top of the slick contained within the boom and suck or scoop the oil into storage tanks on nearby vessels or on the shore. (American Petroleum Institute, 1982: Clark, 1992: Mackay et al, 1980)

A typical example of how oil booms can be used to stop oil spillage from an oil tanker from spreading is shown in figure 2.0.

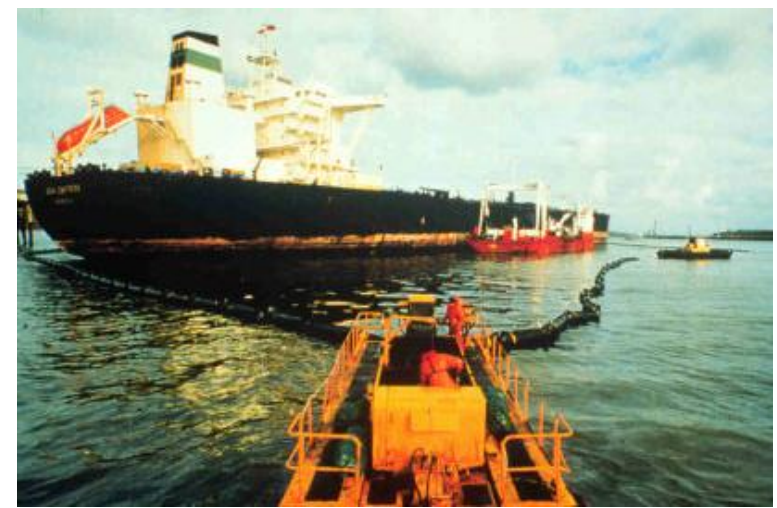

Figure 2.0: Oil booms used to contain oil spill from an oil tanker.

2.3 Chemical dispersants: This method of cleaning oil spillage is best applicable when the sea is rough, the surrounding wind having a high velocity and marine life under treat. Dispersants help surface oil slicks mix into the water, reducing the immediate risk to seabirds and shorelines. Decisions on whether or not to use dispersants to combat an oil spill must be made in each individual case. The decision will take into account the time since the spill, the weather conditions, the particular environment involved, and the type of oil that has been spilt. Dispersants are most effective when used within an hour or two of the initial spill. Chemical dispersants reduce the surface tension that stops oil and water from mixing. Small droplets of oil are then formed, which helps 
promote rapid dilution of the oil by water movements. The formation of droplets also increases the oil surface area, thus increasing the exposure to natural evaporation and bacterial action. Successful dispersion of oil through the water column can affect marine organisms like deep-water corals and sea grass. It can also cause oil to be temporarily accumulated by sub-tidal seafood. (Lewis et al, 1997: Mackay et al, 1983: McAuliffe et al, 1981).

2.4 In-situ burning: In-situ burning is the controlled burning of oil in a place. The method of burning can be a very effective method of cleaning oil pollution that occurs in open water bodies, such as an oil spill in the ocean. It is also very effective on land areas with limited access. However this method is often limited by wave and wind conditions and by the proximity of the spill to populated areas. It is an inexpensive technique and can be very effective in removing polluted oil. The burning can be very rapid and any resulting ecological damage is less severe compared to some conventional oil removal methods. Furthermore, the concentration of the oil slick must be above a threshold value for it to be possibly ignited into flame. Over a long period of time, oil spilled at sea becomes mixed with water forming an emulsion that is difficult or impossible to ignite. Therefore the in-situ burning can only be applied within a limited period from the time that the spillage took place. (Allen et al, 1993)

\section{Determination Of Oil Spill Response Method In A Marine Envoronment}

No two oil spills are the same. This is because of difference in volume of the spillage, the concentration of the oil slick on the surface of the water, location, weather condition and type of oil. The method that should be employed to contain any particular oil spill should take these factors into consideration. If an oil spill occurs, the first thing to do is to locate and stop the source of the spillage. The next thing to do is to contain the spillage (containing the spillage means to stop the spillage from spreading). After we have successfully contained the spillage, we then finally remove the oil from the marine environment. One of the four methods mentioned in this paper could be used to clean up the spillage. It is worthy to note that, more often than not more than one method is normally applied to clean any oil spillage. We want to determine the condition under which we may apply any of the four methods enumerated in this work.

3.1 When to use Oil Booms and Skimmers: The mechanical method using oil booms and skimmers can only be applied when the sea is calm. It cannot successfully be applied under rough sea waves, high wind velocity or high water waves. The oil booms are placed on the water surface in such a way as to oppose the pollution from being spread by the sea or wind currents. Typical examples of how oil booms and skimmers are used to scoop oil from the water surface are given in figures 3.0 and 4.0.

If an oil spill occurs from an oil tanker which is not too far from the river bank, then the pollution may be contained and finally removed from the surface of the water by following the directive as showed in figure 3.0. Where 1 - Coastline; 2 - oil booms; 3 - accidental oil tanker; 4 - direction of current; 5 - an anchor; 6 - oil spillage

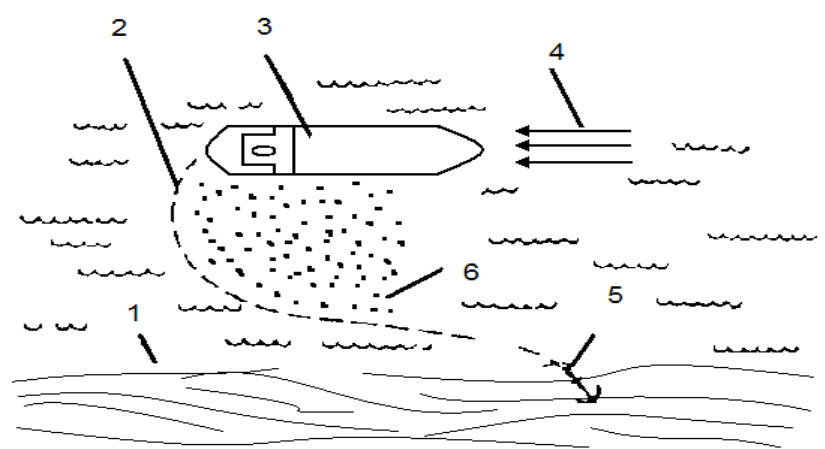

Figure 3.0: Mechanical method of containing oil spillage from an oil Tanker close to the bank of the river.

If however the accident occurs in the middle of the sea, and the sea waves are calm and other conditions favour the use of oil booms and skimmers, then the procedure shown in figure 4.0 may be applied. The speed boats are used to support the oil booms thereby forming a good barrier that can contain (stop the pollution from spreading) the pollution and eventually the oil booms absorbs the oil for final removal from the water. In the place of speed boats, small ships containing containers for putting the oil that is scooped from the water by the oil booms may be used. Oil skimmers may also be introduced within the spillage to assist the oil booms in absorbing the oil. In figure 4.0 the numerical numbers have the following meaning:

1 - Polluting substance (oil spillage) ; 2 - oil booms; 3 - speed boat; 4 - auxiliary speed boat, 5 - oil tanker 


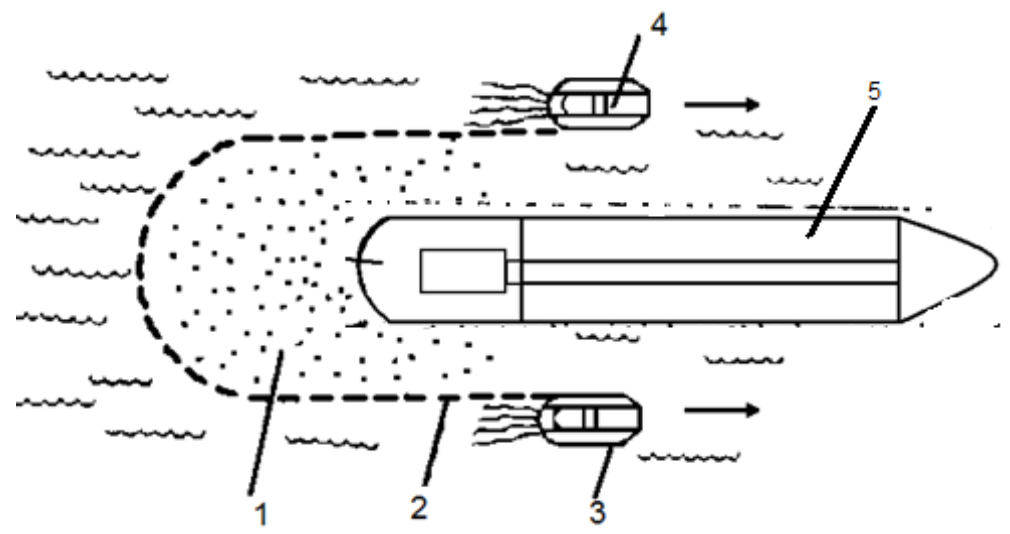

Figure 3.2: Mechanical method of containing and eventual cleaning of oil spillage in open waters.

The technique of removing oil mechanically from a marine environment is different for different oil spills. The direction and velocity of the waves and wind are critical factors that must be taken into consideration. For every oil spill the technique for containing and eventual removal of the oil depends on the volume of the spillage, the concentration of the oil slick on the surface of the water, location, weather condition and type of oil, (Gvozdikov et al, 1996)

3.2 When to use Chemical dispersants: Chemical dispersants should be used within one or two hours from the time of the initial spill. This is because dispersants are more effective when used within this period. Chemical dispersants break oil into smaller droplets, which increases the surface area available for bacteria to access. However dispersants are not suitable for all oils and for all locations. Dispersants reduces the surface tension that stops oil and water from mixing. Small droplets of oil are formed which increases the oil surface area, thereby increasing the exposure to evaporation and bacterial action, (Lewis et al, 1997: Mackay et al, 1983). The use of chemical dispersants to combat any oil spill can affect marine organisms like deep-water corals and sea grass. It can also cause other sea organisms like fish and other aquatic organism to temporarily accumulate oil. Decisions on whether or not to use dispersants to combat an oil spill must be made in each individual case. The right decision must take into account the time since the spill, the weather conditions, the particular environment involved, and the type of oil that has been spilt. Chemical dispersants are normally applied from the air by an aircraft as showed in the figure 5.0. Chemical dispersants may also be applied using speed boats.

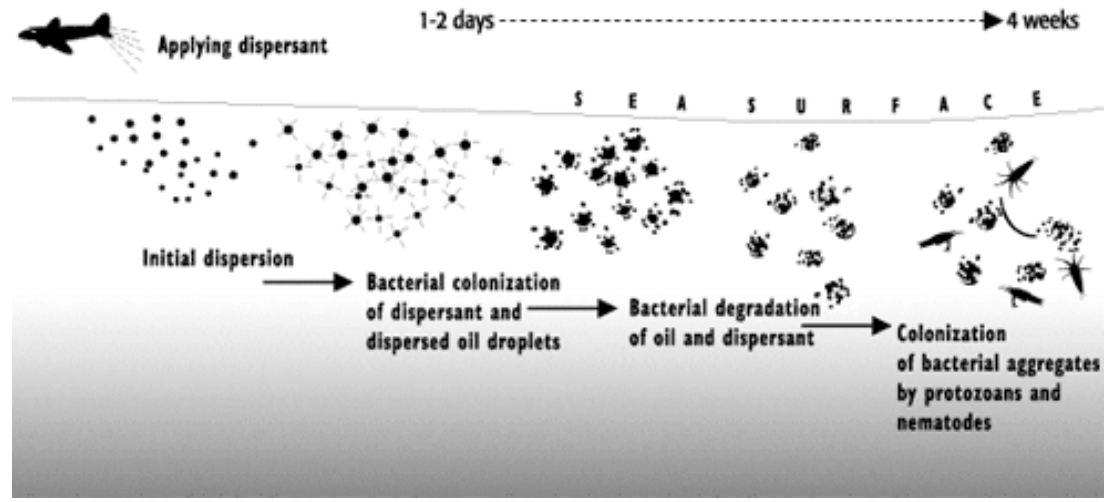

Figure 5.0: Image courtesy of NOAA Office of Response and Restoration

3.3 When to allow the oil to undergo Natural disintegration: This method of combating oil spillage is best applicable when the environmentally sensitive areas are not under threat. The oil is allowed by itself to be broken down by bacteria and other microorganisms into harmless substances such as fatty acids and carbon dioxide. Fertilizing nutrients such as nitrogen and phosphorous that speeds up the process of biodegradation by stimulating the growth of the necessary microorganisms may be added. Decision to add fertilizing agents must take factors such as whether the fertilizer is water soluble or applied in pellet or liquid form (Biello, 2010 and Leahy et al, 1990) 


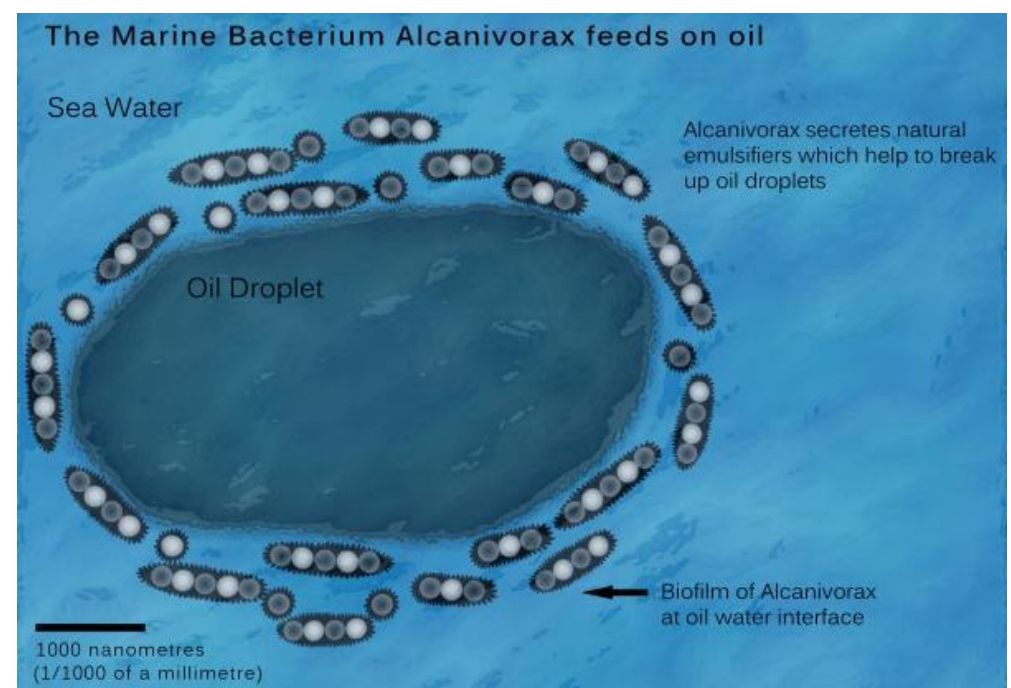

Figure 5: Marine bacterium Alcanivorax feeds on oil ( courtesy: David J. Robinson, 2011).

3.4 When to use In-situ burning: The method of In-situ burning is best applicable in the open waters, where there are no floating vessels like ships, speed boats, oil tankers etc. Normally an aircraft is flown above the waters to ensure that there are no floating objects. Once this has been ascertained, the next thing to be considered is the concentration of the oil slick above the water. According to Obi et al, (2008), the minimum concentration (thickness) of the oil slick on the surface of the water that permits the use of in-situ burning is $3 \mathrm{~mm}$. this is because of the fact that if the thickness of the oil slick is less than $3 \mathrm{~mm}$, it will be very difficult and almost impossible to ignite the slick into flame. One method of determining the concentration of the oil slick on the surface of the sea is by the use of a mathematical model.

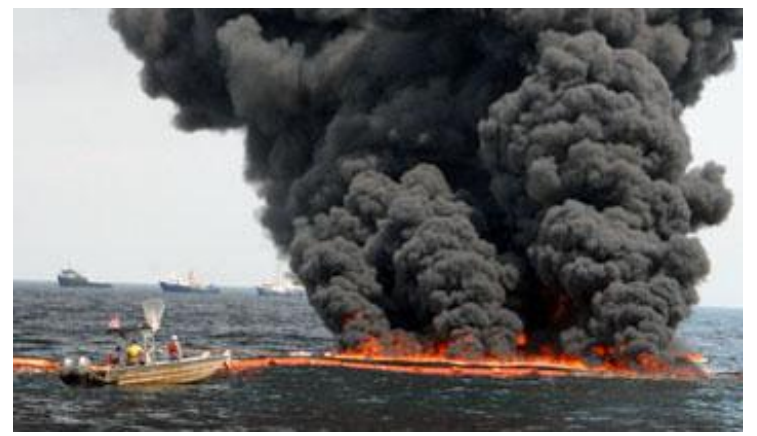

Figure 6: In situ burning of an oil slick, or part of a slick, before it reaches the coast

In figure 6, NOAA worked with the Coast Guard and others to employ in-situ burning during the 2010 Deepwater Horizon/BP oil spill in the Gulf of Mexico. (U.S. Coast Guard). To combat this oil spill, the workers used a fire-proof boom to contain the spread of the oil, and then ignite it. This technique is more successful if the oil is fresh and the weather relatively calm.

\section{Result and discussion:}

The study shows that the mechanical method of combating oil spillage is the best method. The limitation of this method makes it difficult to apply it for all oil spills. The other methods namely biodegradation, chemical dispersants and in-situ burning are not considered to be the best method because they have negative effects on the environment. However, sometimes we are constrained to use them if we must protect the environmentally sensitive areas like beaches, estuaries, etc. It is worthy to note that the environmental impact of the combating technique must be carefully evaluated before usage. This is very necessary as the application of chemical dispersants for instance may cause more harm than the spillage would have caused. Furthermore, the application of in-situ burning may in addition to polluting the atmosphere it may also destroy marine organisms and floating vessels. In many cases it is impossible to use one method alone to clean an oil spill. We may start the cleaning process by employing the mechanical method. Later on it may not be economically wise to continue using this method, we may then apply fertilizing agents and allow the remaining oil to under natural biodegradation. 


\section{Conclusion:}

Oil spills have a negative effect on the environment no matter how quick the spill is removed from the environment. We must therefore do everything humanly possible to stop oil from polluting our environment. However, if oil eventually pollutes the environment, we must first identify the source of pollution and stop it. The next thing we must do is to contain the spillage. We may then employ one or more of the four methods enumerated in this paper to clean the spill from the environment. The environmental impact of any combating technique must be carefully studied before the actual usage.

\section{References}

[1]. Allen A.A., and R.J. Ferek. 1993. Advantages and disadvantages of burning spilled oil. Proceedings of the 1993 International Oil Spill Conference: pp. $765-772$.

[2]. American Petroleum Institute. 1982. Oil Spill Response: Options For MinimizingAdverse Ecological Impacts. American Petroluem Institute Publication No. 4398. Washington, DC. 98 pp.

[3]. Biello, David. Slick Solution: How Microbes Will Clean Up the Deepwater Horizon Oil Spill. Scientific American, May 25, 2010. http://www.scientificamerican.com/article.cfm?id=how-microbes-clean-up-oil-spills

[4]. Clark, R.B. (1992). Marine Pollution. 3rd ed., Gookcraft Ltd., Great Britain, UK, pp. 50-60.

[5]. David J. Robinson (2011) Collaborative experiments online in a module presente globally, in Bioscience Education (18)

[6]. Fay, J.A. (1971). "Physical Processes in the Spread of Oil on a Water Surface", Proc. of the Joint Conf. On the Prevention and Control of Oil Spills, 463-467.

[7]. Leahy, Joseph G. and Rita R. Colwell. Microbial Degradation of Hydrocarbons in the Environment. Microbiological Reviews, September 1990, p. 305-315. Vol. 54, No. 3.

[8]. Lee, K. and E. M. Levy. 1989a. Biodegradation of petroleum in the marine environment and its enhancement. In: Aquatic Toxicology and Water Quality Management, J. O. Nrigau and J. S. S. Lakshminarayana (eds.). New York: John Wiley \& Sons. pp. 218-243

[9]. Lee, K. and E. M. Levy. 1989b. Enhancement of the natural biodegradation of condensate and crude oil on beaches of Atlantic Canada. Proceedings of the 1989 OilSpill Conference, February 13-16, 1989, San Antonio, Texas, pp. 479-486.

[10]. Lehr, W.J., Cekirge, H.M., Fraga, R.J. and Belen, M.S. (1984). "Empirical Studies of the Spreading of Oil Spills", Oil and Petrochemical Poll., 2, 7-11.

[11]. Lewis A. and D. Aurand (1997): Putting dispersants to work: overcoming of obstacles. An issue paper prepared for the 1997 oil spill conference. API: Washington, DC, Technical Report IOSC-004, 80 pgs.

[12]. Mackay, D., Paterson, S. and Trudel, K. (1980). A mathematical model of oil spill behavior. Environmental Protection Service, Fisheries and Environment Canada Report EE-7.

[13]. Mackay, D. and P.G. Wells. 1983. Effectiveness, behavior, and toxicity of dispersants. Proceedings of the 1983 Oil Spill Conference, February 28-March 3, 1983, San Antonio, Texas, pp. 65-71.

[14]. McAuliffe, C.D., B.L. Steelman, W.R. Leek, D.E. Fitxgeral, J.P. Ray, and C.D. Barker.1981. The 1979 Southern California dispersant treated research spills,Proceedings of the 1981 Oil Spill Conference, March 2-5, 1981, Atlanta, Georgia, pp. $269-282$.

[15]. NOAA. (2010) Deepwater Horizon/BP oil spill in the Gulf of Mexico. US Coast Guard Obi, E. O. and Shapasnikova, T. L (2008): Mathematical model of oil spillage in the coastal waters of the Republic of Nigeria. A scientific Journal for Ph.D and D.Sc Research, Russia, No. 4, 2008

[16]. Stolzenbach, K.D., Madsen, O.S., Adams, E.E., Pollack, A.M. and Cooper, C.K. (1977). A Review and Evaluation of Basic Techniques for Predicting the Behavior of Surface Oil Slicks. Report No. 222, Ralph M. Parsons Laboratory For Water Resources and Hydrodynamics, Department of Civil Engineering, MIT, USA.

[17]. Tkalich, P., Huda, M. K., Gin, K. Y. H. (2003). A multipurpose oil spill model. Journal of Hydraulic research vol. 41 No 2.

[18]. Warluzel, A. and Benque, J.P. (1981). “Un Modèle Mathématique De Transport Et D'Etalement D’Une Nappe D'Hydrocarbures", Proc. of Conf. Mechanics of Oil Slicks, Paris, 199-211.

[19]. Gvozdikov V. K. and Zakharov V. M., Technical Means of Liquidating Spills of Oil products: Reference Manual [in Russian], Rostov-on-Don (1996). 